\title{
CLONING AND MUTATION SITES ANALYSIS OF A PUTATIVE HD3A-LIKE GENE IN ELEVEN FOXTAIL MILLET CULTIVARS
}

\author{
Xiaoping Jia ${ }^{1, *}$, Lingfeng Dai ${ }^{1}$, Jianzhang Quan ${ }^{2}$, Zhiyong Li $^{2}$, Bingyou Fan ${ }^{1}$, Hongxiao Zhang ${ }^{1}$, \\ Feiyan Y $u^{1}$, Dianyun Hou ${ }^{1}$ and Guo-an Shi ${ }^{1}$
}

\author{
${ }^{1}$ College of Agriculture, Henan University of Science and Technology, No. 70 Tian Jin Road Jian Xi District, \\ Luoyang, Hennan Province 471003, People's Republic of China; ${ }^{2}$ Institute of Millet Crops, Hebei Academy of \\ Agricultural and Forestry Sciences, No. 162 Hengshan Street, Hi-tech Development Zone, Shijiazhuang, Hebei \\ Province 050031, People's Republic of China. \\ *Corresponding author's e-mail: jiaxiaoping2007@163.com
}

\begin{abstract}
Heading date $3 a(H d 3 a)$, a rice ortholog of $F T$ gene, promotes transition to flowering under short-day conditions. Here a putative $H d 3 a$-like gene was cloned in eleven foxtail millet cultivars including "8322-14", "An04-5014", Jigu1, Jigu27, "Jiyecong4", Longgu26, "Xianzihui", Yugu1, Zheng8041, Zhenggu2 and Zhengzhou12. Totally 26 mutation sites including 23 SNPs and 3 Indels were found among 11 Hd3a-like gene sequences. All the mutation sites arose only from the variation of two cultivars, Jigu27 and "An04-5014", which led to a premature termination at Aa107 of Jigu27 Hd3a protein and quite a few frame-shift mutations after Aa137 of "An04-5014" Hd3a protein. LD analysis found a large LD structure which included 15 SNP sites and 2 Indel sites. Finally, association analysis between 26 mutation sites and eight phenotypic traits including plant height (PH), heading date (HD), panicle length (PL), ear diameter (ED), panicle weight (PW), spikelet number (SN), grain number per branch (GN) and 1000-grain weight (1000-GW) was performed, only PH was correlated with 18 mutation sites $(\mathrm{p}<0.05)$.
\end{abstract}

Keywords: Foxtail millet, $H d 3 a$ gene, single nucleotide polymorphism, insertion-deletion, linkage disequilibrium analysis, association analysis

\section{INTRODUCTION}

Heading date $3 a(H d 3 a)$ gene was identified from a QTL for rice heading date, which located on the short arm of chromosome 6 (Yamamoto et al., 1998), and further study proved that this gene was a functional ortholog of the Arabidopsis FT gene (Kojima et al., 2002). Under short-day (SD) conditions, $H d 3 a$ gene was shown to be up-regluated by Hdl (Heading date 1) and Ehdl (Kojima et al., 2002; Doi et al., 2004). Night break could strongly suppress the mRNA of $H d 3 a$, while this effect could be abolished by phyB mutation, indicating that the night break was mediated by phytochrome B (Izawa et al., 2002; Ishikawa et al., 2005). Recent studies have suggested that $H d 3 a$ gene was a florigen-type mobile flowering signal, its expression level was closely related with flowering time (Lin et al., 2007; Tamaki et al., 2007).

In Northern China, around 6,000 BC, foxtail millet was domesticated from $S$. viridis and became a major cereal crop (Bettinger et al., 2010). As a SD plant, foxtail millet was sensitive to photoperiod, which limited its plant regions. By now, only a few cultivars like Yugu1 and Yugu18 show insensitivity to photoperiod, growing well in a wide range of ecological regions in China. The progress in genomic studies (Zhang et al., 2012; Bennetzen et al., 2012) make it feasible to uncover the molecular mechanism of photoperiod sensitivity in foxtail millet as the key regulators for photoperiodic flowering were conserved among different graminaceous crops. Here we found a putative $H d 3 a$ gene by BLAST search of foxtail millet genomic database (https://phytozome.jgi.doe.gov/pz/portal.html) with rice $H d 3 a$ gene sequence, and cloned this gene from eleven foxtail millet cultivars, primarily analyzed the relationship between Hd3a gene mutation sites and eight phenotypic traits including plant height $(\mathrm{PH})$, heading date (HD), panicle length (PL), ear diameter (ED), panicle weight (PW), spikelet number (SN), grain number per branch (GN) and 1000-grain weight (1000-GW), which provided the basic information for exploring the function of foxtail millet $H d 3 a$ gene in-depth.

\section{MATERIALS AND METHODS}

Totally eleven foxtail millet cultivars, "8322-14", "An045014”, Jigu1, Jigu27, "Jiyecong4”, Longgu26, “Xianzihui", Yugu1, Zheng8041, Zhenggu2 and Zhengzhou12 were selected to clone $H d 3 a$ gene and to investigate eight phenotypic traits including plant height $(\mathrm{PH})$, heading date (HD), panicle length (PL), ear diameter (ED), panicle weight (PW), spikelet number (SN), grain number per branch (GN) and 1000-grain weight (1000-GW). The foxtail millet seeds were sown in experimental field of Zhoushan campus, Henan 
University of Science and Technology on May 15, 2014. The planting pattern: two rows per cultivar, distance between rows was $25 \mathrm{~cm}$ and distance between plants was $3 \sim 5 \mathrm{~cm}$. Tender leaves from 4 leaf stage seedlings were selected for DNA extracting.

The $H d 3 a$ gene sequence from rice (Accession number: NC_029261.1) was used to blast search of foxtail millet genome database deposited in phytozome10.3 (http://phytozome.jgi.doe.gov/pz/ portal.html). As a result, a foxtail millet $H d 3 a$-like gene mRNA sequence coding 178 aa and its genomic sequence were found (Accession number: XM_004964742 and NW_004675964.1). A pair of specific primers (F-CATTTCTCCACTGACGACTTA, RCAGGTCTCAGCCAAGTACAA) was designed to amplify genomic sequence of $\mathrm{Hd} 3 \mathrm{a}$-like gene from 11 foxtail millet cultivars. PCR reactions were performed in $25 \mu$ l volumes: 50 ng of genomic DNA, $200 \mu \mathrm{M}$ dNTPs, $2.5 \mu 1$ 10×PCR buffer, $0.5 \mu \mathrm{M}$ each of forward and reverse primer, 1.25 U Taq DNA polymerase (Tiangen, Beijing, China). The PCR profile was: pre-denaturation at $95^{\circ} \mathrm{C}$ for $4 \mathrm{~min}$, followed by 35 cycles of $40 \mathrm{~s}$ at $94^{\circ} \mathrm{C}, 40 \mathrm{~s}$ at $56^{\circ} \mathrm{C}$ and $1 \mathrm{~min}$ at $72^{\circ} \mathrm{C}$, a last extension of $72^{\circ} \mathrm{C}$ for $5 \mathrm{~min}$. The PCR production was cloned to pMD18 vector (Takara, Dalian, China), then transformed to DH5 $\alpha$ competent cells (Takara, Dalian, China). The positive clones were sent to Sunbiotech Company (Beijing, China) for sequencing. The Clustal 1.8 software was used to perform multiple sequence alignment and the Tassel 2.1 software was used to perform preliminary association analysis between $H d 3 a$-like gene mutation sites and eight phenotypic traits

\section{RESULTS AND DISCUSSION}

All of the eight phenotypic traits showed wide variation range among 11 foxtail millet cultivars (Table 1). According to HD, eleven foxtail millet cultivars could be divided into three groups: long-HD group which included five cultivars from Henan province, Yugu1, Zheng8041, “An04-5014”, Zhengzhou12 and Zhenggu2, medium-HD group which included three cultivars from Hebei province, Jigu1, Jigu27 and "8322-14", short-HD group which included one cultivar from Shandong province ("Jiyecong4"), one cultivar from Heilongjiang province (Longgu26) and one cultivar from Inner Mongolia ("Xianzihui"). As all the eleven cultivars grew in Luoyang, Henan province in this study, five native cultivars showed longer $\mathrm{HD}$, the remaining six from northward regions showed shorter HD, which indicated that foxtail millet cultivars from high latitudes gave obvious photoperiodical reaction when planted in short-day regions.

Sequence alignment results of $\mathrm{Hd} 3$ a-like gene from 11 foxtail millet cultivars, showed 26 mutation sites, which included 23 SNPs and 3 Indels. Of the 26 mutation sites, 13 SNPs and 1 Indel existed in exon 4, 9 SNPs and 1 Indel existed in intron 3 , the remaining $1 \mathrm{SNP}$ and 1 Indel existed in intron 1 (Table 2). Interestingly, all the 26 mutation sites arose from only two foxtail millet cultivars, Jigu27 and "An04-5014". Based on the $H d 3 a$-like gene mRNA sequence of Yugu1, the putative protein sequences of $11 \mathrm{Hd} 3 \mathrm{a}$-like genes were predicted. The results showed that compared with other ten foxtail millet cultivars, the protein sequence of Jigu27 prematurely terminated when reached 107 aa, while the protein sequence of "An04-5014" produced quite a few frame-shift mutations after 137 aa and led to termination codon disappearing due to the Indel in exon 4 (Fig. 1). Linkage disequilibrium (LD) analysis of the 26 mutation sites, a large LD structure was found, which included 17 sites, SNP 415, SNP 421, SNP 424, SNP 441, SNP 452, SNP 460, SNP 476, SNP 480, SNP 485, SNP 498, SNP 499, SNP 503, SNP 504, Indel 507, SNP 512, SNP 513 and Indel 1194 (Fig. 2).

Table 1. Measured values of eight phenotypic traits in eleven foxtail millet cultivars.

\begin{tabular}{|c|c|c|c|c|c|c|c|c|}
\hline & $\begin{array}{l}\text { Plant height } \\
\text { (PH) cm }\end{array}$ & $\begin{array}{l}\text { Head date } \\
\text { (HD) days }\end{array}$ & $\begin{array}{c}\text { Panicle } \\
\text { length }(P L)\end{array}$ & $\begin{array}{c}\text { Ear } \\
\text { diameter } \\
\text { (ED) }\end{array}$ & $\begin{array}{c}\text { Panicle } \\
\text { weight }(\mathbf{P W})\end{array}$ & $\begin{array}{c}\text { Spikelet } \\
\text { number } \\
(\mathbf{S N})\end{array}$ & $\begin{array}{c}\text { Grain } \\
\text { number per } \\
\text { branch } \\
(\mathbf{G N})\end{array}$ & $\begin{array}{c}\text { 1000-grain } \\
\text { weight } \\
(1000-G W)\end{array}$ \\
\hline "8322-14" & 128.4 & 50 & 22.6 & 5.6 & 8.7 & 130.0 & 23.4 & 2.9 \\
\hline "An04-5014" & 122.5 & 65 & 21.6 & 7.6 & 16.8 & 102.0 & 72.0 & 2.8 \\
\hline Jigu1 & 112.0 & 58 & 17.7 & 7.2 & 13.3 & 86.0 & 44.5 & 2.5 \\
\hline Jigu27 & 56.8 & 51 & 7.5 & 3.2 & 0.8 & 58.0 & 7.0 & 2.1 \\
\hline "Jiyecong4" & 106.4 & 47 & 13.3 & 4.2 & 5.4 & 113.0 & 19.8 & 2.0 \\
\hline Longgu26 & 63.1 & 44 & 6.8 & 3.0 & 0.6 & 59.0 & 10.0 & 0.7 \\
\hline "Xianzihui" & 90.4 & 41 & 14.3 & 5.1 & 3.3 & 70.5 & 13.5 & 2.2 \\
\hline Yugu1 & 118.2 & 62 & 18.6 & 7.1 & 10.6 & 112.0 & 35.5 & 2.1 \\
\hline Zheng8041 & 137.9 & 60 & 21.6 & 8.2 & 14.6 & 99.0 & 60.0 & 2.0 \\
\hline Zhenggu2 & 117.2 & 63 & 18.0 & 5.6 & 10.6 & 92.0 & 57.6 & 2.5 \\
\hline Zhengzhou12 & 127.8 & 69 & 15.4 & 6.6 & 12.1 & 80.3 & 52.2 & 2.8 \\
\hline
\end{tabular}

Note: The entire length unit was "cm" the weight unit was "g", the unit of HD was "day". 
Table 2. Mutation sites detected in Hd3a gene sequences of 11 foxtail millet cultivars.

\begin{tabular}{|c|c|c|c|c|c|c|c|c|c|c|c|c|c|c|c|c|c|c|c|c|c|c|c|c|c|c|}
\hline \multirow[b]{2}{*}{ Taxa } & \multicolumn{14}{|c|}{ Exon 4} & \multicolumn{10}{|c|}{ Intron 3} & \multicolumn{2}{|c|}{ Intron 1} \\
\hline & 344 & 359 & 361 & 367 & 368 & 369 & 372 & 415 & 421 & 424 & 441 & 452 & 460 & 476 & 480 & 485 & 498 & 499 & 503 & 504 & 507 & 512 & 513 & 565 & 1194 & 1196 \\
\hline "8322-14" & $\mathrm{T}$ & $\mathrm{T}$ & $\mathrm{C}$ & $\mathrm{C}$ & $\mathrm{C}$ & 0 & $\mathrm{C}$ & G & $\mathrm{G}$ & G & $\mathrm{T}$ & $\mathrm{T}$ & $\mathrm{G}$ & $\mathrm{C}$ & $\mathrm{C}$ & $\mathrm{A}$ & $\mathrm{C}$ & $\mathrm{C}$ & $\mathrm{C}$ & A & 2 & G & $\mathrm{T}$ & $\mathrm{C}$ & 1 & $\mathrm{C}$ \\
\hline "An04-5014" & A & $\mathrm{C}$ & G & $\mathrm{T}$ & $\mathrm{T}$ & 1 & A & G & G & G & $\mathrm{T}$ & $\mathrm{T}$ & G & $\mathrm{C}$ & $\mathrm{C}$ & A & $\mathrm{C}$ & $\mathrm{C}$ & $\mathrm{C}$ & A & 2 & G & $\mathrm{T}$ & $\mathrm{T}$ & 1 & $\mathrm{C}$ \\
\hline Jigu1 & $\mathrm{T}$ & $\mathrm{T}$ & $\mathrm{C}$ & $\mathrm{C}$ & $\mathrm{C}$ & 0 & $\mathrm{C}$ & G & G & $\mathrm{G}$ & $\mathrm{T}$ & $\mathrm{T}$ & $\mathrm{G}$ & $\mathrm{C}$ & $\mathrm{C}$ & A & $\mathrm{C}$ & $\mathrm{C}$ & C & A & 2 & G & $\mathrm{T}$ & $\mathrm{C}$ & 1 & C \\
\hline Jigu27 & $\mathrm{T}$ & $\mathrm{T}$ & $\mathrm{C}$ & $\mathrm{C}$ & $\mathrm{C}$ & 0 & $\mathrm{C}$ & A & A & A & G & G & $\mathrm{T}$ & $\mathrm{G}$ & $\mathrm{T}$ & $\mathrm{T}$ & A & G & $\mathrm{T}$ & G & 0 & $\mathrm{~T}$ & A & $\mathrm{C}$ & 0 & G \\
\hline "Jiyecong4" & $\mathrm{T}$ & $\mathrm{T}$ & $\mathrm{C}$ & $\mathrm{C}$ & $\mathrm{C}$ & 0 & $\mathrm{C}$ & G & $\mathrm{G}$ & G & $\mathrm{T}$ & $\mathrm{T}$ & $\mathrm{G}$ & $\mathrm{C}$ & $\mathrm{C}$ & A & $\mathrm{C}$ & $\mathrm{C}$ & $\mathrm{C}$ & A & 2 & G & $\mathrm{T}$ & $\mathrm{C}$ & 1 & $\mathrm{C}$ \\
\hline Longgu 26 & $\mathrm{~T}$ & $\mathrm{~T}$ & $\mathrm{C}$ & $\mathrm{C}$ & $\mathrm{C}$ & 0 & $\mathrm{C}$ & G & $\mathrm{G}$ & G & $\mathrm{T}$ & $\mathrm{T}$ & $\mathrm{G}$ & $\mathrm{C}$ & $\mathrm{C}$ & A & $\mathrm{C}$ & $\mathrm{C}$ & $\mathrm{C}$ & A & 2 & $\mathrm{G}$ & $\mathrm{T}$ & $\mathrm{C}$ & 1 & $\mathrm{C}$ \\
\hline "Xianzihui" & $\mathrm{T}$ & $\mathrm{T}$ & $\mathrm{C}$ & $\mathrm{C}$ & $\mathrm{C}$ & 0 & $\mathrm{C}$ & G & G & G & $\mathrm{T}$ & $\mathrm{T}$ & G & $\mathrm{C}$ & $\mathrm{C}$ & A & $\mathrm{C}$ & $\mathrm{C}$ & $\mathrm{C}$ & A & 2 & G & $\mathrm{T}$ & $\mathrm{C}$ & 1 & $\mathrm{C}$ \\
\hline Yugu1 & $\mathrm{T}$ & $\mathrm{T}$ & $\mathrm{C}$ & $\mathrm{C}$ & $\mathrm{C}$ & 0 & $\mathrm{C}$ & G & G & G & $\mathrm{T}$ & $\mathrm{T}$ & G & $\mathrm{C}$ & $\mathrm{C}$ & A & $\mathrm{C}$ & $\mathrm{C}$ & $\mathrm{C}$ & A & 2 & G & $\mathrm{T}$ & $\mathrm{C}$ & 1 & $\mathrm{C}$ \\
\hline Zheng8041 & $\mathrm{T}$ & $\mathrm{T}$ & $\mathrm{C}$ & $\mathrm{C}$ & $\mathrm{C}$ & 0 & $\mathrm{C}$ & G & $\mathrm{G}$ & G & $\mathrm{T}$ & $\mathrm{T}$ & $\mathrm{G}$ & $\mathrm{C}$ & $\mathrm{C}$ & A & $\mathrm{C}$ & $\mathrm{C}$ & $\mathrm{C}$ & A & 2 & G & $\mathrm{T}$ & $\mathrm{C}$ & 1 & $\mathrm{C}$ \\
\hline Zhenggu2 & $\mathrm{T}$ & $\mathrm{T}$ & $\mathrm{C}$ & $\mathrm{C}$ & $\mathrm{C}$ & 0 & $\mathrm{C}$ & G & $\mathrm{G}$ & G & $\mathrm{T}$ & $\mathrm{T}$ & G & $\mathrm{C}$ & $\mathrm{C}$ & A & $\mathrm{C}$ & $\mathrm{C}$ & $\mathrm{C}$ & A & 2 & G & $\mathrm{T}$ & $\mathrm{C}$ & 1 & $\mathrm{C}$ \\
\hline Zhengzhou 12 & $\mathrm{~T}$ & $\mathrm{~T}$ & $\mathrm{C}$ & $\mathrm{C}$ & $\mathrm{C}$ & 0 & $\mathrm{C}$ & G & $\mathrm{G}$ & $\mathrm{G}$ & $\mathrm{T}$ & $\mathrm{T}$ & $\mathrm{G}$ & C & $\mathrm{C}$ & A & $\mathrm{C}$ & $\mathrm{C}$ & C & A & 2 & $\mathrm{G}$ & $\mathrm{T}$ & C & 1 & $\mathrm{C}$ \\
\hline
\end{tabular}

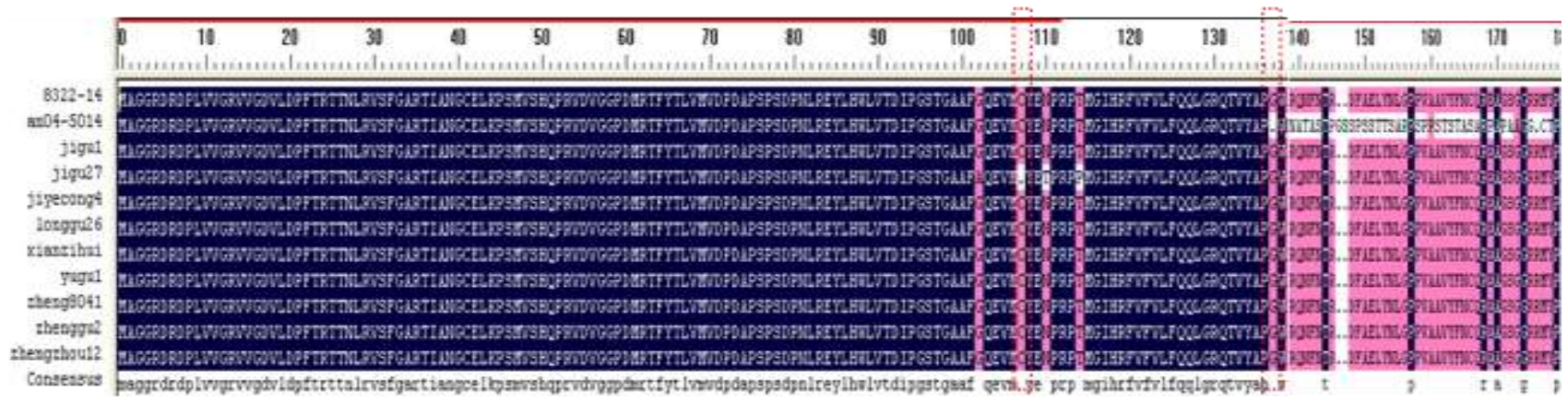

Figure 1. Multiple alignments of $11 \mathrm{Hd3a-like} \mathrm{gene} \mathrm{protein} \mathrm{sequences.}$

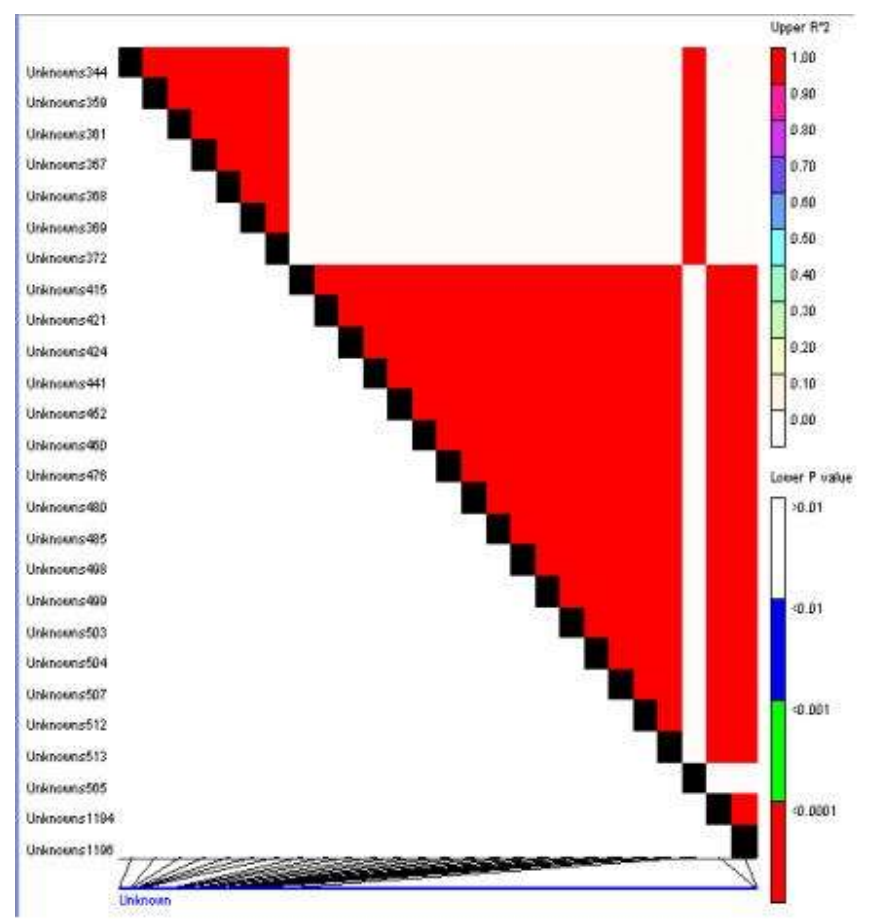

Figure 2. Linkage disequilibrium analysis of 26 mutation sites detected in Hd3a-like gene sequences of 11 foxtail millet cultivars.

Preliminary association analysis between 26 mutation sites and eight phenotypic traits was performed. Only $\mathrm{PH}$ was found to correlate with 18 mutation sites, SNP 415, SNP 421, SNP 424, SNP 441, SNP 452, SNP 460, SNP 476, SNP 480, SNP 485, SNP 498, SNP 499, SNP 503, SNP 504, Indel 507, SNP 512, SNP 513, Indel 1194 and SNP 1196 (Table 3). Except SNP 1196, the remaining 17 correlated sites were just as same as those constituted the large LD structure.

Table 3. Eighteen mutation sites associated with plant height.

\begin{tabular}{lclc}
\hline Trait & \multicolumn{2}{c}{ Mutation sites } & P-value \\
\hline Plant height $(\mathrm{PH})$ & 415 & (SNP) & 0.0375 \\
& 421 & (SNP) & 0.0375 \\
424 & (SNP) & 0.0375 \\
441 & (SNP) & 0.0375 \\
452 & (SNP) & 0.0375 \\
460 & (SNP) & 0.0375 \\
476 & (SNP) & 0.0375 \\
480 & (SNP) & 0.0375 \\
485 & (SNP) & 0.0375 \\
498 & (SNP) & 0.0375 \\
499 & (SNP) & 0.0375 \\
503 & (SNP) & 0.0375 \\
& 504 & (SNP) & 0.0375 \\
507 & (Indel) & 0.0375 \\
512 & (SNP) & 0.0375 \\
& 513 & (SNP) & 0.0375 \\
1194 & (Indel) & 0.0375 \\
& 1196 & (SNP) & 0.0375 \\
\hline
\end{tabular}


In this study, the mutation sites of $H d 3 a$-like gene mainly distributed in intron 3 and exon 4, only two mutation sites were found in intron 1 , which indicated that $\mathrm{N}$-terminal region of the $\mathrm{Hd} 3 \mathrm{a}$-like gene was more conservative than that of Carboxyl-terminal region. The putative protein sequences of $H d 3 a$-like gene also showed that the first 100 amino acids from N-terminal were highly conservative among 11 foxtail millet cultivars, which was in accord with that reported in rice (Kojima et al., 2002). Association analysis showed the mutation sites of $\mathrm{Hd} 3 \mathrm{a}$-like gene were correlated with plant height $(\mathrm{PH})$ in foxtail millet, no mutation sites associated with heading date were found. While in rice, $H d 3 a$ gene was identified as a QTL for heading date located on the short arm of chromosome 6 (Yamamoto et al., 1998), and the expression of $H d 3 a$ gene under SD conditions could promote heading (Kojima et al., 2002). The reason that no mutation sites were found to be associated with heading date in this study may be attributed to the sequence coverage analyzed. The sequence diversity of promoter region was proven to be highly correlated with expression level of $H d 3 a$ gene, giving diverse heading date (Takahashi et al., 2009). In this study, only the complete coding region of $H d 3 a$-like gene was analyzed, not containing the promoter region. Furthermore, the expression level of $H d 3 a$ gene was regulated by $H d l$ and Ehdl in rice (Kojima et al., 2002; Doi et al., 2004). As the orthologs of $H d l$ and $E h d l$ were not cloned and analyzed in this study, it was difficult to clarify the relationship between Hd3a-like gene sequence mutation and heading date. So, clone $H d l$ and Ehdl-like gene, analyze promoter region and expression level of $H d 3 a$-like gene should be the next work.

Conclusion: Totally 26 mutation sites were detected in Hd3alike gene of eleven foxtail millet cultivars, which led to prematurely terminated at 107 aa of Jigu27 and quite a few frame-shift mutations after 137 aa, termination codon disappearing of "An04-5014". Preliminary association analysis between 26 mutation sites and eight phenotypic traits showed that only plant height was associated with 18 mutation sites, most of which laid in a LD structure.

Acknowledgements: I thank Prof. Ping Lu for providing foxtail millet strains, this work was supported by the National Natural Science Foundation of China (Grant No. 31471569).

\section{REFERENCES}

Bennetzen, J.L., J. Schmutz, H. Wang, R. Percield and J.
Hawkins. 2012. Reference genome sequence of the model plant Setaria. Nat. Biotechnol. 30:555-561.

Bettinger, R.L., L. Barton and C. Morgan. 2010. The origins of food production in north China: A different kind of agricultural revolution. Evol. Anthropol. 19:9-21.

Doi, K., T. Izawa, T. Fuse, U. Yamanouchi, T. Kubo, Z. Shimatani, M. Yano and A. Yoshimura. 2004. Ehd1, a Btype response regulator in rice, confers short-day promotion of flowering and controls FT-like gene expression independently of Hd1. Genes Dev. 18:926936.

Ishikawa, R., S. Tamaki, S. Yokoi, N. Inagaki, T. Shinomura, M. Takano and K. Shimamoto. 2005. Suppression of the floral activator $\mathrm{Hd} 3 \mathrm{a}$ is the principal cause of the night break effect in rice. Plant Cell 17:3326-3336.

Izawa, T., T. Oikawa, N. Sugiyama, T. Tanisaka, M. Yano and K. Shimamoto. 2002. Phytochrome mediates the external light signal to repress FT orthologs in photoperiodic flowering of rice. Genes Dev. 16:20062020.

Kojima, S., Y. Takahashi, Y. Kobayashi, L. Monna, T. Sasaki, T. Araki and M. Yano. 2002. Hd3a, a rice ortholog of the Arabidopsis FT gene, promotes transition to flowering downstream of $\mathrm{Hd} 1$ under short-day conditions. Plant Cell Physiol. 43:1096-1105.

Lin, M.K., H. Belangerb, Y.J. Leec, E. Varkonyi-Gasicb, K.I. Taokaa, E. Miuraa, B. Xoconostle-Cázaresa, K. Gendlere, R.A. Jorgensene, B. Phinneyc, T.J. Loughb and W.J. Lucasa. 2007. FLOWERING LOCUS $\mathrm{T}$ protein may act as the long-distance florigenic signal in the cucurbits. Plant Cell 19:1488-1506.

Takahashi, Y., K.M. Teshima, S. Yokoi, H. Innan and K. Shimamoto. 2009. Variations in Hd1 proteins, Hd3a promoters, and Ehd1 expression levels contribute to diversity of flowering time in cultivated rice. Proc. Natl. Acad. Sci. USA 106:4555-4560.

Tamaki, S., S. Matsuo, H.L. Wong, S. Yokoi and K. Shimamoto. 2007. Hd3a protein is a mobile flowering signal in rice. Sci. 316:1033-1036.

Yamamoto, T., Y. Kuboki, S.Y. Lin, T. Sasaki and M. Yano. 1998. Fine mapping of quantitative trait loci $\mathrm{Hd}-1, \mathrm{Hd}-2$ and $H d-3$, controlling heading date of rice, as single Mendelian factor. Theor. Appl. Genet. 97:37-44.

Zhang, G.Y., X. Liu, Z.W. Quan, S.F. Cheng and X. Xu. 2012. Genome sequence of foxtail millet (Setaria italica) provides insights into grass evolution and biofuel potential. Nat. Biotechnol. 30:549-554. 